\title{
Racismo y xenofobia en México
}

DOI: https://doi.org/10.32870/dse.v0i13.247

\section{Gisela Carlos Fregoso*}

\section{Reseña}

Yankelevich, Pablo (2015). Inmigración y racismo. Contribuciones a la historia de los extranjeros en México. México: El Colegio de México, Centro de Estudios Históricos, 237 pp.

El libro Inmigración y racismo. Contribuciones a la historia de los extranjeros en México, de Pablo Yankelevich, es una excelente opción de lectura incluso para aquellos no expertos en el tema, ya que nos acerca a un fenómeno que es muy común no sólo en México sino en diversas latitudes: el racismo y la xenofobia. Pero, ¿cómo hablar de ello si México se ha distinguido por la recepción de políticos extranjeros o de colectivos como la migración española o aquellos provenientes del cono sur? Ello nos hace pensar que México siempre ha estado abierto a la migración. Pero no es así. Este libro, divido en seis capítulos y con un trabajo riguroso de tipo archivístico y bibliográfico como sustento, nos habla de cómo México en tanto Estado nación ha tratado a los extranjeros. Tarea que funge a manera de espejo, ya que dice más sobre el propio Estado mexicano y sus prácticas cotidianas, que de los propios inmigrantes, como si hiciéramos el ejercicio de revisar cómo trata Jalisco a los ochocientos mil indígenas que aquí viven (INEGI, 2015), a los más de sesenta mil afromexicanos (INEGI, 2015), y a los cuatro mil extranjeros (INEGI, 2010) que residen en el estado.

El motor que le ha llevado a Pablo Yankelevich a coordinar este material es reflexionar y profundizar sobre un conjunto de paradojas bajo las cuales se fundamenta el mestizaje, entre las que destaca revisar cómo es que México fue parte de los países con medidas migratorias más restrictivas de América Latina durante el siglo XX. Es en este sentido que Yankelevich comparte su duda con los lectores al preguntarse: ¿cómo, al mismo tiempo en que se daban tendencias xenofílicas, se tiene evidencia de prácticas de segregación como el antichinismo al norte del país? Aunque México ya no tiene leyes de discriminación negativa explícita que nieguen el acceso a colectivos particulares, es curioso observar, si tomamos como ejemplo el estado de Jalisco, que la entidad cuenta con poco más de ochenta mil extranjeros, de los cuales se tienen registrados sólo a doscientas cincuenta y ocho personas de origen chino en la segunda ciudad más grande del país (INEGI, 2010). ¿Cómo explicar esto?

* Doctora en Investigación Educativa por el Instituto de Investigaciones en Educación de la Universidad Veracruzana, sede Xalapa, Veracruz. Correo electrónico: carlosfregosogisela@hotmail.com 
David Scott Fitzgerald y David Cook-Martin, quienes están a cargo de la primera parte del libro, nos muestran que las políticas de inmigración del último siglo han obedecido a tendencias internacionales y a reconfiguraciones geopolíticas. Antes se tenían leyes explícitas de discriminación negativa que perjudicaban a negros y a chinos en países como Estados Unidos, Canadá o México. Años más tarde, durante la primera mitad del siglo XX, esas leyes cambiaron debido a un movimiento internacional de corte antirracista y ya no se habló de discriminación negativa, sino de capacidad de asimilación: ello quiere decir que había métodos de selección étnica disimulados bajo argumentos políticamente correctos. Sin embargo, argumentan los autores, este movimiento antirracista era hipócrita ya que en el ámbito internacional se decía "no a la xenofobia", pero se ejercía el racismo hacia dentro de los Estados nación a través de diversos mecanismos o bajo argumentos científicos. Algo así como las inconformidades de mexicanos contra los argumentos racistas de Donald Trump, pero dentro del país continúa habiendo expresiones abiertamente discriminatorias como la de "pinche indio mugroso".

El capítulo dos nos plantea el caso de las teorías eugenésicas y el uso que se les daba en la medida en que aumentaban los flujos migratorios a escala mundial. Andrés H. Reggiani nos comenta aquí el paralelismo que existía entre la diseminación de los saberes científicos y el aumento de la xenofobia. La eugenesia latinoamericana tenía la característica de nutrirse de diversos discursos, como del pediátrico o del obstétrico entre otros, con el fin de generar una metadisciplina o disciplina del hombre que permitiera a los Estados nación un mayor "rendimiento del capital humano" (p. 69). De ahí se explica la aplicación de la biotipología sobre pueblos originarios a lo largo y ancho de América Latina; esto es: había un proyecto eugenésico panamericano. Sin embargo, como la escalera del racismo se puede tornar muy resbaladiza y el racismo es heterogéneo, al mismo tiempo en que la comunidad científica latinoamericana intentaba ser partícipe del debate eugenésico internacional, ésta era rechazada en los foros internacionales por prejuicios raciales.

Pero la noción de raza ha tomado rumbos diversos, según nos plantea Tomás Pérez Vejo en el capítulo tres. Antes de la conformación de los Estados nación la cristiandad era el epicentro rector en Occidente. Pero a partir del siglo XVIII, nos dice Pérez, la Ciencia -con mayúsculas-y los Estados se convirtieron en la nueva religión y en los sustentos que le daban lógica al racismo, fenómeno por demás particular o paradójico, ya que los estados pretendían alcanzar la igualdad a través de la ciudadanía. En México el debate sobre la raza tomó dos vertientes: uno que intentaba ubicar a los indígenas en la escala evolutiva y darles un papel en la conformación del Estado nación, y otro que delineó las políticas de inmigración en México para mejorar la raza.

En el capítulo cuatro, el libro da un giro inesperado con el artículo de Cunin. Ella afirma que si bien se diseñaron e intentaron poner en práctica políticas con tintes racistas y xenófobos en México, una cosa era la teoría y otra muy diferente la practicidad de esas políticas en la vida cotidiana, máxime si hablamos de la periferia del país. ¿Cómo entender el ingreso de trabajadores afrobeliceños, con ciudadanía inglesa, que venían a lo que hoy se conoce como Chetumal a trabajar en la ex- 
plotación de maderas y árboles de chicle? Para 1937 México contaba con políticas xenófobas bajo argumentos de asimilación y por ello, desde una visión centralista, el país no permitía el ingreso de trabajadores negros al país. Sin embargo, como bien documenta Cunin, los términos clasificatorios a través de los cuales se regía la oficina de migración en la ciudad de México demuestran lo complejo, relativo y hasta lo arcaico que resultaban las medidas racistas en un lugar como Payo Obispo -ahora Chetumal-. El texto da cuenta de lo complejas y hasta obsoletas que eran las taxonomías de aquel entonces: ¿cómo distinguir una raza africana primitiva de una raza negra, o de una raza negra americana? Lo que se deliberaba en la ciudad de México no repercutía de igual manera en la periferia. En cambio, a diferencia de estados como Quintana Roo en donde parecían no tener efecto las políticas centralistas que estaban encargadas de idear la nación postrevolucionaria, de Sonora y Coahuila provenían algunos de los próceres de la nación -como Elías Calles. De ahí que este artículo demuestre la importancia geopolítica del país o la forma en que estaba diagramado el México postrevolucionario.

Es por eso que el capítulo de Kif Agustine-Adams se vuelve uno de los más reveladores y siniestros del libro. El autor da cuenta de cómo a través de los censos nacionales se pretendía construir la idea de "patria"; cómo el censo de 1930 convirtió en chinos a muchos mexicanos merced a su apariencia y la manera en que éstos después fueron expulsados junto con sus consortes e hijos (mexicanos). El autor da cuenta la forma cómo, a pesar de existir marcos legales en el estado posrevolucionario mexicano -como la constitución de 1917- el Departamento de Estadística en la ciudad de México modificó los datos estadísticos y registró como chinos a infinidad de mexicanos. Los resultados fueron que de los 3571 chinos registrados en el Quinto Censo del estado de Sonora durante el año de 1930, para 1931, sólo quedaban 92 en el estado. Por órdenes del entonces gobernador Rodolfo Calles y con información del censo nacional, varias personas de nacionalidad mexicana y de ascendencia china fueron expulsadas, además de que 300 chinos aproximadamente fueron asesinados bajo el argumento de que éstos no se asimilarían al mestizaje.

Estas políticas no fueron un caso aislado en México. El antisemitismo de la década de los treintas y cuarentas es otro ejemplo. Como documenta el coordinador de libro, Pablo Yankelevich, este tipo de xenofobia no llegó a extremos como el caso de los mexicanos convertidos en chinos, pero sí tuvo sus peculiaridades: aunque en México la comunidad judía era relativamente pequeña, no fue sino hasta que éstos incursionaron en actividades económicas como vendedores ambulantes que fueron vistos como una amenaza tanto para sectores de clase baja como media. Este último sector, señala el autor, fue el que tomó medidas legales con argumentos antisemitas que perseguían el objetivo de la expulsión de la comunidad judía en México, fin que no se consumó. Ahora, si bien no expulsaron a judíos de México bajo un discurso nacionalista, tampoco permitieron la entrada de éstos durante la segunda guerra mundial. El argumento era el mismo: la nación buscaba la asimilación y la integración para así combatir el racismo, de manera que sólo aceptaba a aquellos "fáciles de asimilarse". Así que, según decía su discurso, si llegaban judíos, a los cuales se les tildaba de 
diferentes y no asimilables, se dispararía el racismo. De modo que los argumentos antisemitas y la judeofobia era disfrazada de un discurso antirracista. Como dije, algo similar a lo que hoy ocurre en México, nos escandalizamos por las actitudes racistas de otros países hacia los mexicanos, pero en el interior del país las instituciones no reconocen a los afromexicanos, vulneran los derechos de los pueblos indígenas o se asesina a migrantes centroamericanos. Como bien lo señaló ya Frantz Fanon (2009) en uno de sus textos, no hay racismos mejores ni peores. En todos los casos, considero, existe un proceso de deshumanización que permite que unas vidas sean prescindibles y otras no. Por ello, reitero, éste es un libro apto para todo lector, ya que da cuenta de una las formas como llegamos a ser "la nación mexicana", término por demás trillado en los libros de texto de la educación de México.

\section{Bibliografía}

Fanon, F. (2009). Piel negra, máscaras blancas. Madrid: Akal.

INEGI (2010). Estadistica. Instituto Nacional de Estadistica y Geografía. Recuperado el 04 de abril de 2016, de Instituto Nacional de Estadística y Geografía: http://www.inegi.org.mx/

- (2015). Estadística. Instituto Nacional de Estadística y Geografía. Recuperado el 08 de marzo de 2016, de Instituto Nacional de Estadística y Geografía: http://www.inegi.org.mx/

Yankelevich, P. (2015). Inmigración y racismo. Contribuciones a la historia de los extranjeros en México. México: El Colegio de México. 